This document was prepared in conjunction with work accomplished under Contract No. DE-AC09-96SR18500 with the U.S. Department of Energy.

This work was prepared under an agreement with and funded by the U.S. Government. Neither the U. S. Government or its employees, nor any of its contractors, subcontractors or their employees, makes any express or implied: 1 . warranty or assumes any legal liability for the accuracy, completeness, or for the use or results of such use of any information, product, or process disclosed; or 2 . representation that such use or results of such use would not infringe privately owned rights; or 3 . endorsement or recommendation of any specifically identified commercial product, process, or service. Any views and opinions of authors expressed in this work do not necessarily state or reflect those of the United States Government, or its contractors, or subcontractors. 
Proceedings of PVP2008-61572

2008 ASME Pressure Vessels and Piping Division Conference

July 27-31, 2008, Chicago, Illinois

WSRC-STI-2008-00230

PVP2008-61572

\title{
A Proposed Methodology for Strain-Based Failure Criteria
}

\author{
Tsu-te Wu \\ Savannah River National Laboratory \\ Aiken, South Carolina 29803 \\ (803) 725-8201, tsu-te.wu@srnl.doe.gov
}

\begin{abstract}
This paper proposes an alternative methodology to determine the failure criteria for use in dynamic simulations of radioactive material shipping packages in the events of hypothetical accident conditions. The current stress failure criteria defined in the Nuclear Regulatory Guide 7.6 [1] and the ASME Code, Section III, Appendix F [2] for Level D Service Loads are based on the ultimate strength of uniaxial tensile test specimen rather than on the material fracture in the state of multi-axial stresses. On the other hand, the proposed strain-based failure criteria are directly related to the material failure mechanisms in multi-axial stresses. In addition, unlike the stress-based criteria, the strain-based failure criteria are applicable to the evaluation of cumulative damages caused by the sequential loads in the hypothetical accident events as required by the Nuclear Regulatory Guide 7.8 [4].
\end{abstract}

\section{INTRODUCTION}

In packaging design, structural failures due to material rupture in the events of Hypothetical Accident Conditions (HAC) are prevented by application of stress limits, which are specified in Nuclear Regulatory Guide 7.6 [1] and the ASME Code, Section III, Appendix F [2]. However, the stress-based failure criteria are not able to evaluate cumulative damages in the events of the sequential HAC loading as defined in Nuclear Regulatory Guide 7.8 [4].

Alternative structural acceptance criteria based on strains instead of stress were previously proposed [5], [6]. However, these criteria are rather simplified and not entirely based on failure mechanism of ductile metal.

The methodology proposed in this paper for determining failure criteria are based on strains rather than stresses. The acceptable strain limits are established based on the damage initiation mechanism during the progressive damage process of ductile metals. Consequently, the proposed methodology is more in line with the failure mechanism of ductile metals.

\section{FAILURE MECHANISM OF DUCTILE METAL}

The stiffness degradation process of ductile metals can be modeled using damage mechanics [3],[7]. Material failure of ductile metals can be illustrated by the response of a typical metal specimen during a uniaxial tensile test shown in Figure 1. The true stress-true strain curve of material response is initially linear elastic, $\mathrm{a}-\mathrm{b}$, followed by plastic yielding with strain hardening, $\mathrm{b}-\mathrm{c}$. Beyond point $\mathrm{c}$ there is a marked reduction of load-carrying capacity until rupture, c - d. The deformation during this last phase is localized in a neck region of the specimen. Point $\mathrm{c}$ identifies the material state at the onset of damage, which is referred to as the damage initiation criterion. Beyond this point, the stress-strain response $\mathrm{c}-\mathrm{d}$ is governed by the evolution of the degradation of the stiffness in the region of strain localization. In the context of damage mechanics c - $d$ can be viewed as the degraded response of the curve $c-d$ ' so that the material would have followed in the absence of damage.

Thus, the specification of a failure mechanism consists of three distinct parts:

1. The definition of the effective (or undamaged) material response (e.g., a - b - c - d' in Figure 1);

2. A damage initiation criterion (e.g., c in Figure 1);

3. A damage evolution law (e.g., c - d in Figure 1);

Material failure can be defined as the loss of load-carrying capacity that results from progressive degradation of the material stiffness. As illustrated in Figure 1, Point c corresponds to the maximum load-carrying capability of 
the uniaxial tensile test specimen and the stress at Point c is the material ultimate strength. The allowable limits of stress intensities in the cases of plastic-system and plasticcomponent analyses for Level D service loads defined in the ASME Code, Section III, Appendix F [2] are based on the lower bound value of the ultimate stresses of uniaxial tensile test specimens. The allowable limits of stress intensities for austenitic steel are as follows.

1. The general primary membrane stress intensity $P_{m}$ shall not exceed the greater of $0.7 S_{u}$ and $S_{y}+1 / 3$ $\left(\mathrm{S}_{\mathrm{u}}-\mathrm{S}_{\mathrm{y}}\right)$;

2. The maximum primary stress intensity at any location shall not exceed $0.90 \mathrm{~S}_{\mathrm{u}}$.

3. The average primary shear across a section loaded in pure shear shall not exceed $0.42 \mathrm{~S}_{\mathrm{u}}$.

Where $\mathrm{S}_{\mathrm{u}}$ and $\mathrm{S}_{\mathrm{y}}$ denote the ultimate and yield stresses, respectively.

Based on the same principle adopted in the ASME Code for the stress-based criteria described above, it is reasonable to define the allowable values of the equivalent plastic strains as the equivalent plastic strain corresponding to the damage initiation point. The equivalent plastic strain corresponding to the damage initiation is designated by $\varepsilon_{e, o}^{p l}$ in Figure 1 for the uniaxial tensile test. However, the equivalent plastic strain at the onset of material damage of ductile metal varies with stress triaxiality, which is the ratio of the hydrostatic pressure and the von Mises equivalent stress. Therefore, if the structure experiences multi-axial stresses, the equivalent plastic strains at the onset of structural damage is not a single fixed value and can not be represented by the equivalent plastic strain at the onset of damage obtained from the uniaxial tensile test. The determination of the equivalent plastic strain at damage initiation is discussed in the following section.

\section{DAMAGE INITIATION MODELS}

Damage initiation and fracture of ductile metal is mainly caused by two mechanisms; namely, (1) the ductile fracture due to the nucleation, growth, and coalescence of voids; and (2) the shear fracture due to shear band localization. The phenomenological models of ductile and shear criteria for damage initiation discussed in [3] and [7] are adopted in this paper.

\section{Ductile Criterion of Damage Initiation}

The model based on ductile criterion is applicable for predicting the onset of damage due to nucleation, growth, and coalescence of voids. It assumes that the equivalent plastic strain at the onset of damage, $\varepsilon_{e, d}^{p l}$, is a function of stress triaxiality and strain rate; namely,

$$
\varepsilon_{e, d}^{p l}\left(T_{f}, \frac{d \varepsilon_{e}^{p l}}{d t}\right)
$$

where

$$
T_{f}=\frac{-p}{q}
$$

is the stress triaxiality factor, $p$ is the hydrostatic pressure, $q$ is the Mises equivalent stress, and $\frac{d \varepsilon_{e}^{p l}}{d t}$ is the equivalent plastic strain rate. The function $\varepsilon_{e, d}^{p l}$ can be determined experimentally. The analytical expression of the ductile damage initiation given by Hooputra [3], [7] is as follows.

$$
\begin{aligned}
& \varepsilon_{e, d}^{p l}\left(T_{f}, \frac{d \varepsilon_{e}^{p l}}{d t}\right) \\
& =\frac{\varepsilon_{t}^{+} \sinh \left[k_{d}\left(T_{f}^{-}-T_{f}\right)\right]+\varepsilon_{t}^{-}\left[k_{d}\left(T_{f}-T_{f}^{+}\right)\right]}{\sinh \left[k_{d}\left(T_{f}^{-}-T_{f}^{+}\right)\right]}
\end{aligned}
$$

where $\varepsilon_{t}^{+}$and $\varepsilon_{t}^{-}$denote the equivalent plastic strain at ductile damage initiation for equi-biaxial tensile and equibiaxial compressive strains, respectively; $T_{f}^{+}$and $T_{f}^{-}$denote the stress triaxiality factors in equi-biaxial tensile and equi-biaxial compressive stresses; $k_{d}$ denotes a material parameter.

The criterion for damage initiation is met when the following condition is satisfied:

$$
\omega_{d}=\int \frac{d \varepsilon_{e}^{p l}}{\varepsilon_{e, d}^{p l}}=1
$$

where $\omega_{d}$ is a state variable. The ductile criterion can be used in conjunction with the Mises plasticity.

The three parameters, $\varepsilon_{t}^{+}, \varepsilon_{t}^{-}$and $k_{d}$ in Equation (3) must be determined experimentally. 
The values of $T_{f}^{+}$and $T_{f}^{-}$are determined from Equation (2) in the following manner.

The hydrostatic stress, $p$ and equivalent stress, $q$ expressed in terms of the principal components are:

$$
p=-\frac{1}{3}\left(\sigma_{1}+\sigma_{2}+\sigma_{3}\right)
$$

and

$q=\frac{1}{\sqrt{2}}\left[\left(\sigma_{1}-\sigma_{2}\right)^{2}+\left(\sigma_{2}-\sigma_{3}\right)^{2}+\left(\sigma_{3}-\sigma_{2}\right)^{2}\right]^{\frac{1}{2}}$

1). For equi-biaxial tensile state,

$$
\sigma_{1}=\sigma_{2}=\sigma \text { and } \sigma_{3}=0
$$

The following value of the stress triaxiality factor in the equi-biaxial tensile state can then be obtained from Equations (1) and (5) through (7):

$$
T_{f}^{+}=\frac{2}{3}
$$

2). For equi-biaxial compressive state,

$$
\sigma_{1}=\sigma_{2}=-\sigma \text { and } \sigma_{3}=0
$$

The following value of the stress triaxiality factor in the equi-biaxial compressive state can then be obtained from Equations (1), (5), (6) and (9):

$$
T_{f}^{-}=-\frac{2}{3}
$$

\section{Shear Criterion of Damage Initiation}

The model based on shear criterion is applicable for predicting the onset of damage due to shear band localization. It assumes that the equivalent plastic strain at the onset of damage, $\varepsilon_{e, s}^{p l}$, is a function of the shear stress ratio and strain rate:

$$
\varepsilon_{e, s}^{p l}\left(\theta_{s}, \frac{d \varepsilon_{e}^{p l}}{d t}\right)
$$

were $\theta_{s}=\left(q+k_{s} p\right) / \tau_{\max }$ is the shear stress ratio, $\tau_{\max }$ is the maximum shear stress, and $\kappa_{s}$ is a material parameter. The function $\varepsilon_{e, s}^{p l}$ can be determined experimentally. The analytical expression of the shear damage initiation given by Hooputra [3], [7] is as follows.

$\varepsilon_{e, s}^{p l}\left(\theta_{s}, \frac{d \varepsilon_{e}^{p l}}{d t}\right)$

$$
=\frac{\varepsilon_{s}^{+} \sinh \left[f\left(\theta_{s}-\theta_{s}^{-}\right)\right]+\varepsilon_{s}^{-} \sinh \left[f\left(\theta_{s}^{+}-\theta_{s}\right)\right]}{\sinh \left[f\left(\theta_{s}^{+}-\theta_{s}^{-}\right)\right]}
$$

where

$$
\theta_{s}=\frac{\left(1-k_{s} T_{f}\right)}{\phi}
$$

with

$$
\phi=\frac{\tau_{\max }}{q}
$$

In the above equation, $\tau_{\max }$ denotes the maximum shear stress. The material parameters, $f, \varepsilon_{s}^{+}$and $\varepsilon_{s}^{-}$in Equation (12) and $k_{s}$ in Equation (13), must be determined experimentally.

In Equation (12), $\theta_{s}^{+}$and $\theta_{s}^{-}$are the values of $\theta_{s}$ corresponding to the equi-biaxial tensile and equi-biaxial compressive stress states, respectively. Their values are determined in the following manner:

1). For equi-biaxial tensile stress state:

From Equation (7), one obtains

$$
\tau_{\text {max }}=\frac{\sigma-0}{2}=\frac{\sigma}{2}
$$

Then, the following value of $\phi_{s}^{+}$can be obtained from Equations (6), (7), (14) and (15):

$$
\phi_{s}^{+}=0.5
$$


2). For equi-biaxial tensile stress state:

From Equation (9), one obtains

$$
\tau_{\max }=\frac{0+\sigma}{2}=\frac{\sigma}{2}
$$

Then, the following value of $\phi_{s}^{-}$can be obtained from Equations (6), (9), (14) and (17):

$$
\phi_{s}^{-}=0.5
$$

The criterion for damage initiation is met when the following condition is satisfied:

$$
\omega_{s}=\int \frac{d \varepsilon_{e}^{p l}}{\varepsilon_{e, s}^{p l}}=1
$$

where $\omega_{s}$ is a state variable. The shear criterion can be used in conjunction with the Mises plasticity.

\section{EXAMPLE PROBLEM}

The damage initiation models expressed in Equations (3) and (12) are implemented in the ABAQUS computer code [3]. An example problem is analyzed to illustrate the proposed method of the strain-based failure criteria. Figure 2 shows the finite-element model of the system analyzed and the dimensions of the components. The cylinder drops $1016 \mathrm{~mm}$ onto a rigid cylindrical bar of $101.6 \mathrm{~mm}$ in diameter. The length, thickness and outside diameter of the cylinder are $1087.946 \mathrm{~mm}, 142.675 \mathrm{~mm}$ and $695.96 \mathrm{~mm}$, respectively. The material parameters involved in the ductile criterion of damage initiation, Equation (3), and in the shear criterion of damage initiation, Equation (12), are not available for stainless steel materials.

For illustration purpose, the material used is aluminum alloy, EN AW-7108 T6, which is the same material as reported in [3], [7]. The modulus of elasticity is 70000.0 Newton $/ \mathrm{mm}^{2}$ and the Poisson ratio is 0.33 . The density is arbitrarily assumed to be $8.1 \times 10^{-8}$ gram- $\mathrm{sec}^{2} / \mathrm{mm}^{4}$ so that the cylinder is heavy enough to have great damage after the 1016-mm drop. Figure 3 shows the stress-strain curve of static uniaxial tensile test specimen. The stress-strain curve of uniaxial tensile test specimen at strain rate of 250 $1 /$ sec is about the same as the curve shown in Figure 3. The material parameters needed to determine the ductile and shear criteria for damage initiation are given in [3], [7] and are also given in Tables 1 and 2. Using the parameters given in Tables 1 and 2 together with the values given in Equations (8), (10), (16) and (18), the equivalent plastic strains for the ductile damage initiation corresponding to Equation (3) and for the shear damage initiation corresponding to Equation (12) are calculated and shown in Figures 4 and 5, respectively.

The time history of the energy variation of the dynamic simulation is shown in Figure 6, where ALLIE, ALLKE, ALLPD and ALLSE designate the internal, kinetic, plastic dissipation and elastic strain energies, respectively. Figures 7 and 8 are the contour plots of the von Mises stresses and the equivalent plastic strains, respectively.

Figure 9 displays the shear damage initiation criterion indicator, SHRCRT. When the value of SHRCRT is equal to 1 or greater, the shear damage initiation criterion is met. The maximum value of SHRCRT equal to 0.6795 in Figure 9 implies that the equivalent plastic strain reaches $67.95 \%$ of shear damage initiation.

Figure 10 shows the ductile damage initiation criterion indicator, DUCTCRT. The maximum value of DUCTCRT is 0.2739 ; namely, the maximum deformation reaches $27.39 \%$ of the damage initiation criterion when DUCTCRT equal to 1 .

Since the value of SHRCRT is greater than that of DUCTCRT, the analytical results indicate that the cylinder fracture will be caused by shear band localization rather than by the nucleation, growth, and coalescence of voids.

This example problem demonstrates that the phenomenological models of ductile and shear criteria for damage initiation discussed in [3], [7] can be adopted to establish the strain-based failure criteria. For example, the values of the damage initiation criterion indicators, DUCTCRT and SHRCRT, less than 1 such as 0.7 can be selected as the failure criteria.

\section{CONCLUSIONS}

A method of strain-based failure criteria is proposed in this paper for use in the dynamic simulations. The acceptable strain limits are established based on the damage initiation mechanisms in the progressive damage process of ductile metals. Consequently, the proposed strain-based acceptable criteria are more realistic than the current stress-based criteria.

The strain-based failure criteria are particularly useful in the HAC analyses, where the cumulative plastic strains 
from all the sequential events, rather than each individual event, should be addressed.

\section{REFERENCES}

1. 2007 Nuclear Regulatory Guide 7.6.

2. 2007 ASME Boiler and Pressure Vessel Code, Section III, Appendix F.

3. ABAQUS/Explicit User’s Manual, Version 6.6.

4. 2007 Nuclear Regulatory Guide 7.8.

5. Davis, E. A., and Connelly, F. M., "Stress Distribution and Plastic Deformation in Rotating Cylinders of Strain-Hardening Material,” Transactions of the ASME Journal of Applied Mechanics, March 1959.

6. Manjoine, M. J ,’Damage and Failure at Elevated Temperature, " Transactions of the ASME Journal of Pressure Vessel Technology, February 1983.

7. Hooputra, H., H. Gese, H. Dell, and H. Werner, "A Comprehensive Failure Model for Crashworthiness Simulation of Aluminum Extrusions," International Journal of Crashworthiness, Vol. 9, No.5, pp. 449-464, 2004.

\begin{tabular}{|c|c|c|}
\hline $\begin{array}{c}\text { Material } \\
\text { Parameter }\end{array}$ & Static & $\begin{array}{c}\text { Dynamic } \\
\text { (Strain Rate }=\mathbf{2 5 0} \text { 1/sec) }\end{array}$ \\
\hline$\varepsilon_{t}^{+}$ & 0.26 & 0.44 \\
\hline$\varepsilon_{t}^{-}$ & 193.0 & 1494.0 \\
\hline$\kappa_{d}$ & 5.277 & 8.6304 \\
\hline
\end{tabular}

Table 1. Material Parameters for Ductile Failure

\begin{tabular}{|c|c|c|}
\hline $\begin{array}{c}\text { Material } \\
\text { Parameter }\end{array}$ & Static & $\begin{array}{c}\text { Dynamic } \\
\text { (Strain Rate }=\mathbf{2 5 0} \text { 1/sec) }\end{array}$ \\
\hline$\varepsilon_{s}^{+}$ & 0.26 & 0.35 \\
\hline$\varepsilon_{s}^{-}$ & 4.16 & 1.2 \\
\hline$f$ & 4.04 & 2.05 \\
\hline$\kappa_{s}$ & 0.3 & 0.3 \\
\hline
\end{tabular}

Table 2. Material Parameters for Shear Failure 


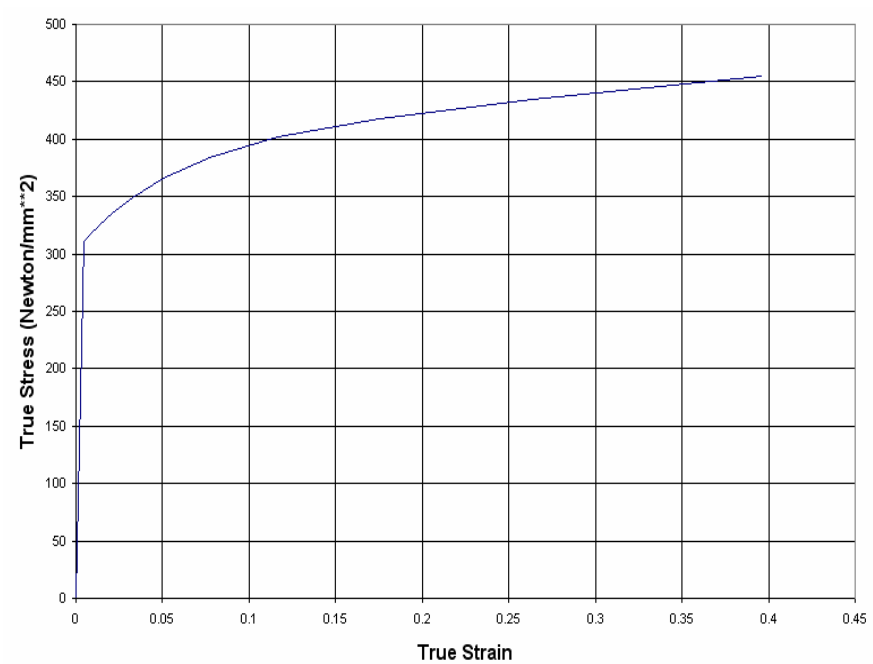

Figure 3. True Stress- True Strain Curve of Uniaxial Tensile Test of Typical Ductile Metal Specimen

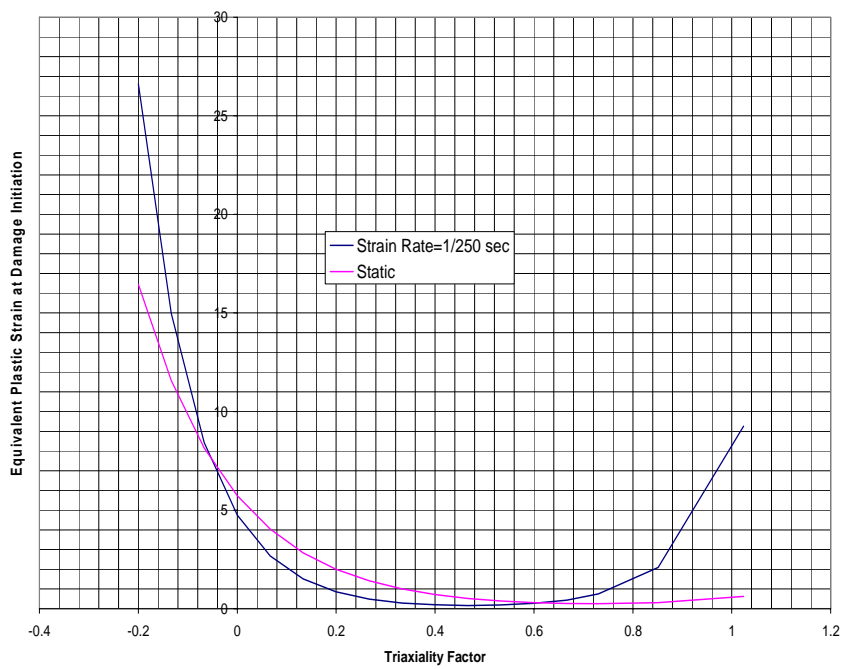

Figure 4. Equivalent Plastic Strain of Ductile Damage Initiation Curves

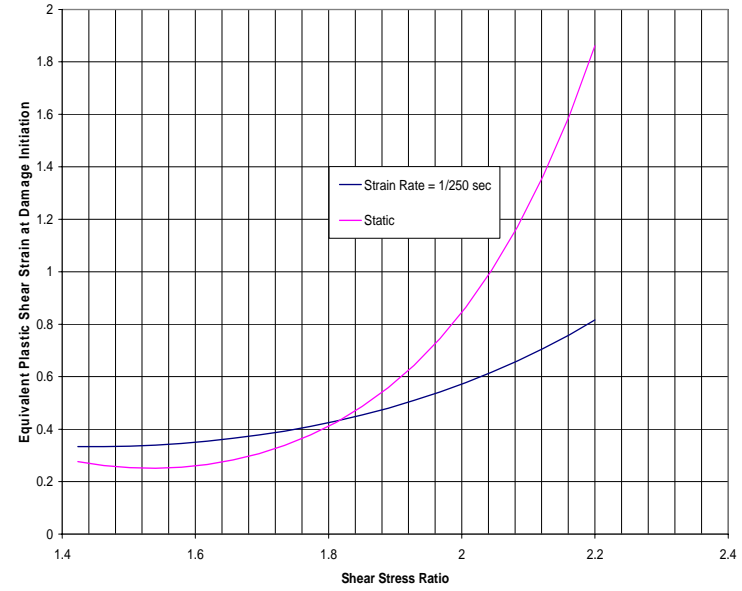

Figure 5. Equivalent Plastic Strain of Shear Damage Initiation Curves

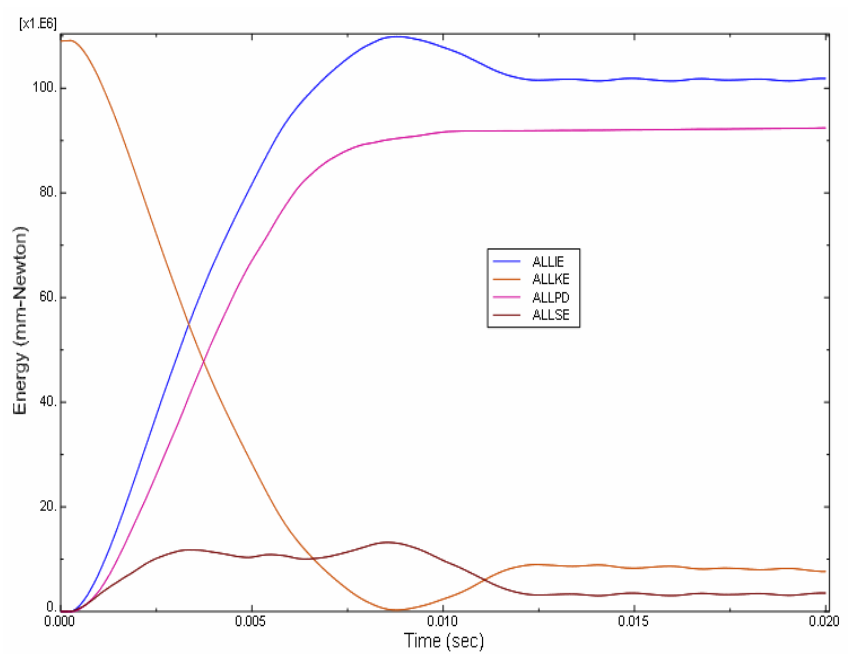

Figure 6. Energy Variation for the 1016-mm Puncture 

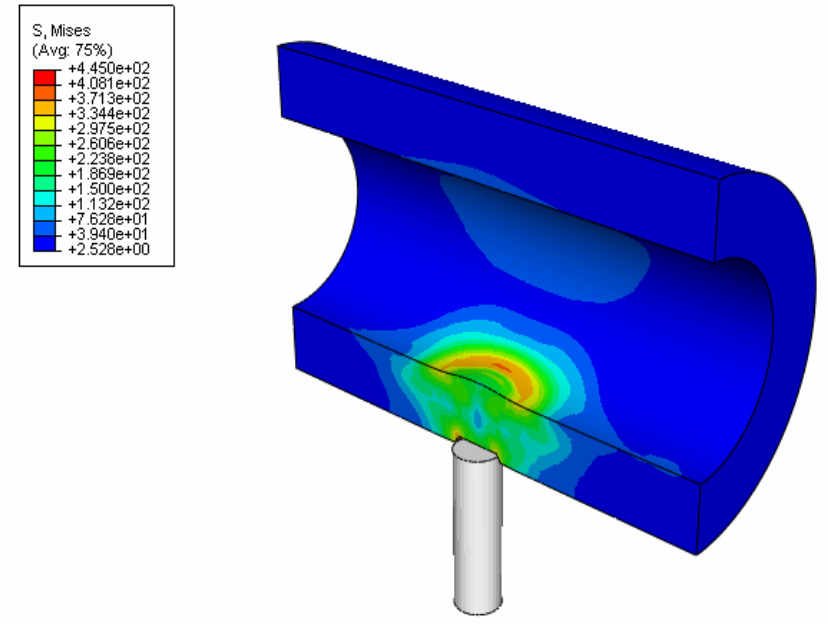

Figure 7. Plot of von Mises Stresses

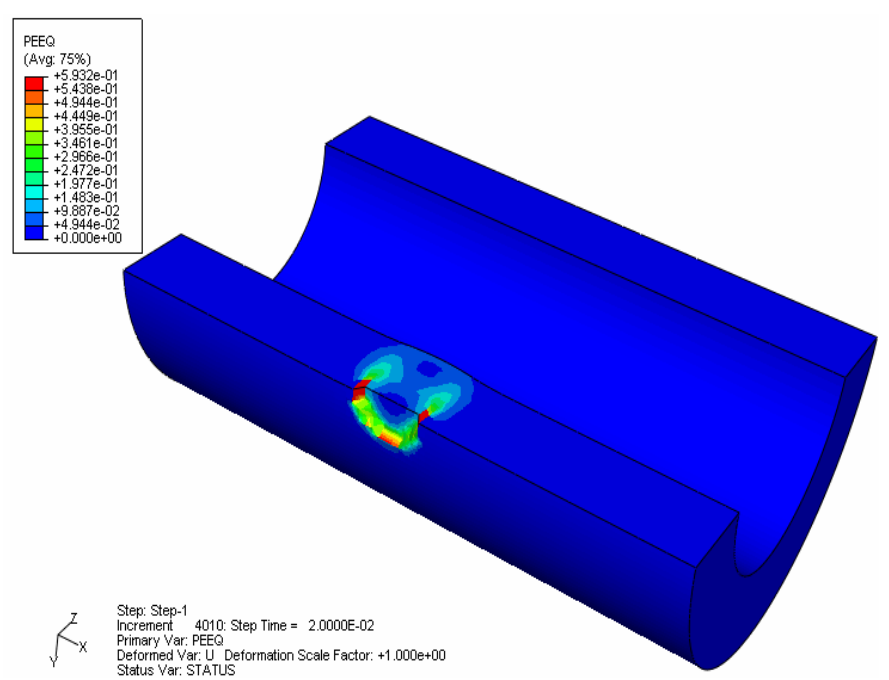

Figure 8. Plot of Equivalent Plastic Strains

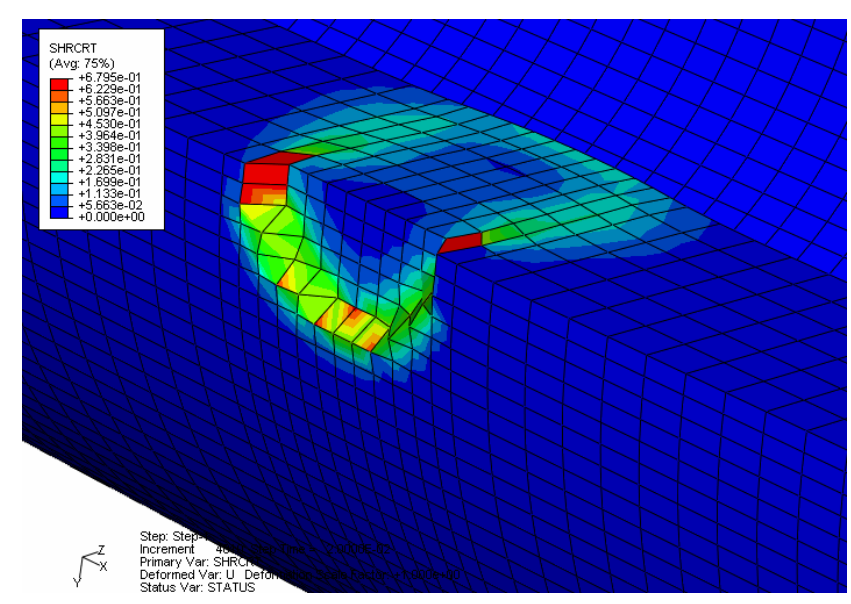

Figure 9. Plot of Shear Damage Initiation Indicator, SHRCRT

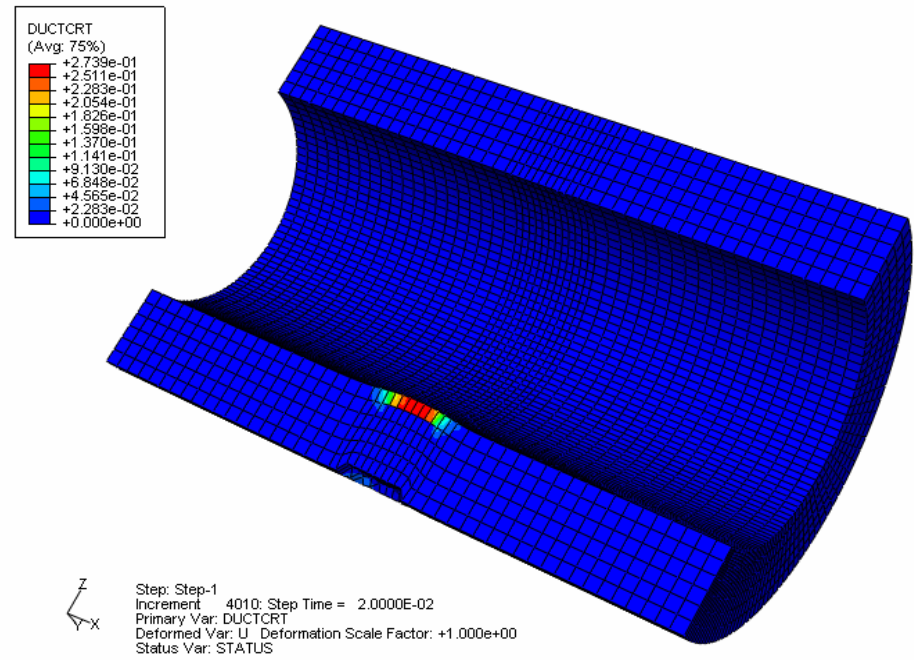

Figure 10. Plot of Ductile Damage Initiation Indicator, DUCTCRT 